Botany Research Journal 4 (2): 23-25, 2011

ISSN: 1995-4751

(C) Medwell Journals, 2011

\title{
Genetic Relationship Analysis among Oakleaf Loquat, Daduhe Loquat and Common Loquat Based on Morphologic Traits
}

\author{
Yan Juan, Wang Yongqing, Luo Nan and Lv Xiulan \\ College of Horticulture, Sichuan Agricultural University, 625014 Ya'an, Sichuan, China
}

\begin{abstract}
Based on morphologic traits including 18 traits of leaf and fruit, the genetic relationships among Oakleaf loquat (E. prinoides), Daduhe loquat (E. prinoides var. dadunensis) and Common loquat (E.japonica) were investigated in this study. The results showed that Oakleaf loquat, Daduhe loquat and Common loquat displayed very significant differences. Many traits of Daduhe loquat were between Oakleaf loquat and Common loquat and some of the other traits were lean to Oakleaf loquat while some were lean to Common loquat. The results of comparative analysis and cluster analysis support that Daduhe loquat was hybrid of Oakleaf loquat and Common loquat.
\end{abstract}

Key words: Oakleaf loquat, Daduhe loquat, Common Loquat, genetic relationship, morphologic traits, China

\section{INTRODUCTION}

Loquat (Eriobotrya japonica Lindl.), originating in China and cultivating between 20 and $35^{\circ}$ latitude is an important perennial fruit crop because of both its economic and ecological attributes (Lin et al., 2004; Hu et al., 2006).

The genus Eriobotrya includes about 30 species. Daduhe loquat a new taxa discovered by Zhang et al. (1990) in Southeast part of Gongga mountain, Sichuan province was classified as a botanical variety of oakleaf loquat.

However, its taxonomic status is questioned. In the researches of Zhang et al. (1990) and Cai (2000) the systematic position of Daduhe loquat was between Oakleaf loquat and Common loquat but slightly leaning to Oakleaf loquat based on the external morphology characteristics of flowers and isozyme; Li et al. (1992) concluded that Daduhe loquat belongs to the same species as Common loquat based on isozyme analysis Tang (1997) analyzed the karyotype of the three genotypes and considered that Daduhe loquat was a separate species from Oakleaf loquat and originated from a hybrid between Oakleaf loquat and Common loquat. Recently, molecular marks such as RAPD, AFLP and ISSR were used to discussed their relationship (Yang et al., 2007; Luo et al., 2011) and the results were consistent with Tang (1997).

In summary, there were two different views about the systematic position of Daduhe loquat. One is Daduhe loquat is a original species of common loquat the other one is it is a hybrid of Oakleaf loquat and Common loquat. In this study, morphologic traits of leaf and fruit were used to analyze the genetic relationships among Oakleaf loquat, Daduhe loquat and Common loquat in order to provide more evidence of the taxonomic status of Daduhe loquat.

\section{MATERIALS AND METHODS}

Shimian, located at Sichuan province of China is recognized worldwide as one of loquat origin place. There are extremely rich in wild loquat.

The material of this study were collected from Shimian and specific circumstances of their geographical and distribution scales were shown in Table 1. Evaluation criterion and assignment of qualitative characters were based on the method described by Zheng et al. (2006). Data were standardized and converted by DPS v3.01, significance between means was tested by Duncan's multiple range test and cluster analysis was carried out by the Unweighted Pair Group method with Arithmetic Mean (UPGMA) method.

Table 1: Geographical and distribution scales by global positioning system Species

(Cultivars) Latitude $\quad$ Longitude $\quad$ Altitude (m)

Oakleaf L. $\quad 29^{\circ} 13^{\prime} 50^{\prime \prime}-29^{\circ} 14^{\prime} 42^{\prime \prime} 102^{\circ} 19^{\prime} 59^{\prime \prime}-102^{\circ} 24^{\prime} 55^{\prime \prime} \quad 857-870$

Daduhe L. $\quad 29^{\circ} 13^{\prime} 11^{\prime \prime}-29^{\circ} 14^{\prime} 57^{\prime \prime} 102^{\circ} 14^{\prime} 39^{\prime \prime}-102^{\circ} 22^{\prime} 14^{\prime \prime} \quad 940-1168$

Common L. $29^{\circ} 15^{\prime} 00^{\prime \prime} \quad 102^{\circ} 18^{\prime} 58^{\prime \prime} \quad 910$

(wild)

$\begin{array}{lll}\text { cv. Dawuxing } 29^{\circ} 14^{\prime} 10^{\prime \prime} & 102^{\circ} 20^{\prime} 34^{\prime \prime} & 927\end{array}$

Corresponding Author: Luo Nan, College of Horticulture, Sichuan Agricultural University, 625014 Ya'an, Sichuan, China 
Bot.Res. J., 4 (2): 23-25, 2011

Table 2: Leaf traits description

\begin{tabular}{lccccccc}
\hline Species (Cultivar) & Leaf shape & Length & Width & L/W & Petiole length & Floss of old leaf back & Leaf margin \\
\hline Oakleaf L. & Ellipse & $15.29^{\mathrm{a}}$ & $6.98^{\mathrm{b}}$ & $2.34^{\mathrm{b}}$ & $2.24^{\mathrm{a}}$ & No & Crinkle \\
Daduhe L. & Ellipse & $17.30^{\mathrm{c}}$ & $6.48^{\mathrm{b}}$ & $2.71^{\mathrm{ab}}$ & $1.15^{\mathrm{b}}$ & Grey or brown & Serrate \\
Common L. & Obovate & $23.93^{\mathrm{b}}$ & $7.03^{\mathrm{b}}$ & $3.43^{\mathrm{a}}$ & $0.85^{\mathrm{c}}$ & Brown & Sparse serrate \\
cv. Dawuxing & Obovate & $28.37^{\mathrm{a}}$ & $7.98^{\mathrm{a}}$ & $3.57^{\mathrm{a}}$ & $1.06^{\mathrm{bc}}$ & Brown & Sparse serrate \\
\hline
\end{tabular}

Means following the same letter within columns were not significantly different. According to Duncan's multiple range test $(p=0.05)$

Table 3: Fruit traits description

\begin{tabular}{|c|c|c|c|c|c|c|c|c|}
\hline Species (Cultivar) & Fruit shape & Apex shape & Caly x cavity & $\begin{array}{l}\text { Longitudinal } \\
\text { D. }(\mathrm{cm})\end{array}$ & $\begin{array}{l}\text { Transverse } \\
\text { D. (cm) }\end{array}$ & $\mathrm{L} / \mathrm{T}$ & Fruit weight & Seed no. \\
\hline Oakleaf L. & Oval & Concave & Close & $1.71^{\mathrm{c}}$ & $1.28^{c}$ & $1.34^{\mathrm{a}}$ & $1.700^{\circ}$ & $1.20^{c}$ \\
\hline Daduhe L. & Suborbicular & Flat & Open & $1.85^{b c}$ & $1.81^{\mathrm{bc}}$ & $1.02^{b}$ & $5.860^{b}$ & $1.45^{\mathrm{c}}$ \\
\hline Common L. & Suborbicular & Flat & Close & $2.20^{b}$ & $2.05^{b}$ & $1.08^{b}$ & $5.730^{b}$ & $2.19^{b}$ \\
\hline cv. Dawuxing & Suborbicular & Concave & Open & $4.09^{\mathrm{a}}$ & $4.16^{a}$ & $0.98^{b c}$ & $45.53^{\mathrm{a}}$ & $2.74^{\mathrm{a}}$ \\
\hline
\end{tabular}

Means following the same letter within columns were not significantly different. According to Duncan's multiple range test $(p=0.05)$

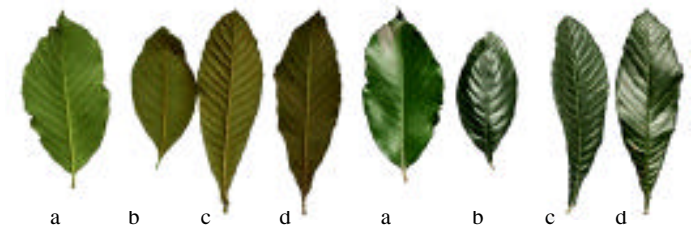

Fig. 1: Leaf picture of loquat; a: Oakleaf loquat; b: Daduhe loquat; c: Common loquat (wild); d: Common loquat cv.Dawuxing

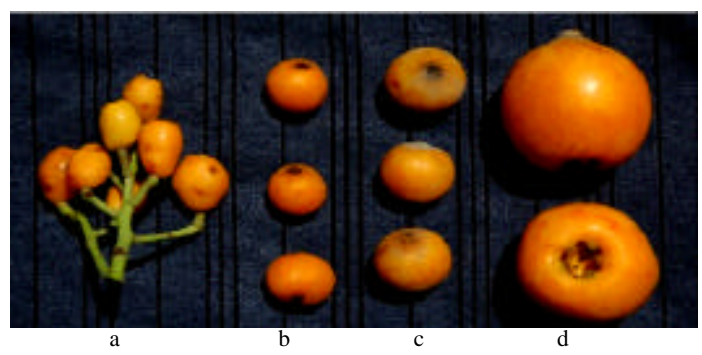

Fig. 2: Fruit picture of loquat; a: Oakleaf loquat; b: Daduhe loquat; c: Common loquat (wild); d: Common loquat cv. Dawuxing

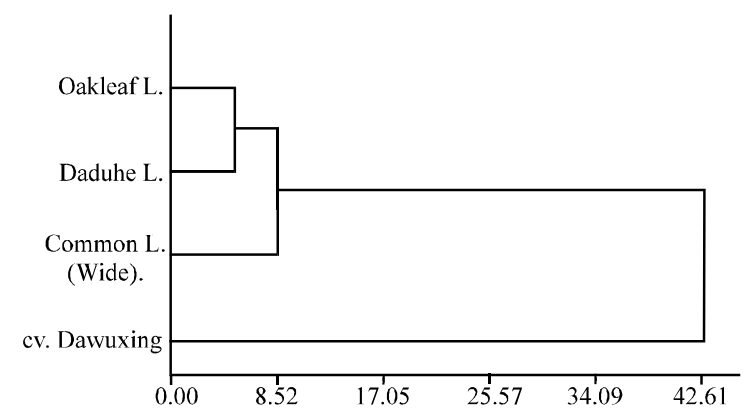

Fig. 3: Clustering result based on the mophylogic traits

\section{RESULTS AND DISCUSSION}

The result shows that Oakleaf loquat, Daduhe loquat and Common loquat displayed very significant differences in leaf and fruit morphology (Table 1 and 2; Fig. 1 and 2). The traits of $\mathrm{L} / \mathrm{W}$ and petiole length of Daduhe loquat were between Oakleaf loquat and Common loquat; leaf shape and width lean to Oakleaf loquat and floss of old leaf back and leaf margin lean to Common loquat (Both wild and $\mathrm{cv}$.).

The traits of longitudinal D. $(\mathrm{cm})$, transverse D. $(\mathrm{cm})$ and seed number of Daduhe loquat were between Oakleaf loquat and Common loquat; fruit shape were the same as Common loquat and L/T lean to Common loquat (Both wild and cv.) Apex shape and fruit weight were the same as wild common loquat; calyx cavity was the same as cv. Dawuxing.

Cluster analysis of Oakleaf loquat, Daduhe loquat and Common loquat was based on 9 morphological traits of leaf and fruit by UMGMP (Fig. 3 and Table 3). The result indicated that there were continuous variation of phenotypic characteristics among Oakleaf loquat, Daduhe loquat and Common loquat.

The systematic position of Daduhe loquat was between Oakleaf loquat and Common loquat but slightly leaning to Oakleaf loquat.

\section{CONCLUSION}

In this research, many traits of leaf and fruit of Daduhe loquat were between Oakleaf loquat and Common loquat, cluster analysis showed the same message. The results of comparative analysis and cluster analysis support that Daduhe loquat was hybrid of Oakleaf loquat and Common loquat.

Thus, the taxonomic status of Daduhe loquat reaches a common understanding on the morphological, isozyme and molecular biology levels that Daduhe loquat was hybrid of Oakleaf loquat and Common loquat which laid a solid foundation for the loquat germplasm and genetic research in world. 


\section{ACKNOWLEDGEMENT}

This research was surpported by the Chinese Ministry of Agriculture (201003073) and the Department of Science and Technology of Sichuan Province (2006YZGG-07-10).

\section{REFERENCES}

Cai, L.H., 2000. The study of allozyme diversity, relationship of species and cultivars classification of Eriobotrya. Ph.D. Thesis, Huazhong Agricultural University, Wuhan, China.

Hu, F.M., X.F. Tan and H.M. Liu, 2006. Cultivation and Utilization of Main Economic Trees in China. China Forestry Press, Beijing, pp: 234-246.

Li, X.L., N.G. Jiang and J.G. Jiang, 1992. Studies on relationship of the genus Etiobotrya in Sichuan. J. Southwest Agric. Univ., 14: 539-542.

Lin, S.Q., X.H. Yang and C.M. Liu, 2004. Physical geography distribution of loquat in China. Acta Horticult. Sin., 31: 569-573.
Luo, N., Y.Q. Wang, Y. Fu and Q. Yang, 2011. Genetic relationships among Eriobotrya prinoides Var. Dadunensis, Eriobotrya prinoides and Eriobotrya japonica using rapd and ISSR markers. Acta Horticult., 887: 59-64.

Tang, B., 1997. The genetic relationship of E. japonica, $E$. daduheensis and E. prinoides. Ph.D. Thesis, Southwest Agricultural University, Chongqing, China.

Yang, X.H., C.M. Liu and S.Q. Lin, 2007. The genetic relationship among common loquat, Daduhe loquat and Oakleaf loquat, according to RAPD and AFLP analysis. Subtrop. Plant Sci., 36: 9-12.

Zhang, H.Z., S.A. Peng, L.H. Cai, 1990. The gemplasm resources of the genus Eriobotrya with special references on the origin of E. japonica Lindl. Acta Hort. Sin., 17: 64-67.

Zheng, S.Q., X.P. Chen and X.D. Xu, 2006. Descriptors and Data Standard for Loquat (Eriobotrya spp.). China Agriculture Press, Beijing. 